\title{
Século XXI - Da educação das certezas à educação na incerteza: um estudo introdutório
}

\author{
Vanderlei Smaniotto* \\ Ireno Antônio Berticelli* ${ }^{* *}$
}

\begin{abstract}
Resumo
Este artigo tem como objetivo elucidar a compreensão filosófica da educação sob as condições do que Zygmunt Bauman denomina modernidade líquida. Aproximamos ciência e educação modernas que, historicamente, se fundaram nas certezas, com suas propostas de ideais duradouros e sólidos pretensamente garantidos por modelos físico-matemáticos. É um olhar sobre a ciência e sobre a educação, numa conjuntura de fluidez e incertezas, para analisar as relações, no horizonte da crise e das incertezas que atinge a ambas na contemporaneidade. Esperamos é situar os processos educacionais no contexto de compreensão do que se denomina correntemente de pósmodernidade ou modernidade líquida.
\end{abstract}

Palavras-chave: Educação; Incerteza; Modernidade líquida.

\section{1st century - From the education of certainties to the education of uncertainty: an introductory study}

\begin{abstract}
This article has as objective to elucidate the philosophical comprehension of education under the conditions that Zygmunt Bauman names liquid modernity. We approximate modern science and education which, historically, where founded on certainties, with their proposals of lasting and solid ideals allegedly guaranteed, by physicalmathematical models. It is a glance on science and education in a conjuncture of fluidity and uncertainty, in order to analyze the relations of proximity between them, in the horizon of crisis and the uncertainties reaching both in contemporary times. What we expect is to situate the educational processes in the context of comprehension of what is designated as liquid modernity.
\end{abstract}

Keywords: Education; Uncertainty; Liquid modernity.

\section{Introdução}

Inicialmente, cabe refletir, ainda que brevemente, sobre os tempos em que vivemos. Partimos das discussões ancoradas na metáfora da modernidade líquida, recursiva nas obras de Zygmunt Bauman (1999a, 1999b, 2001, 2007, 2008a, 2008b, 2010), em que demonstra que nosso tempo é permeado de ações e relações que enaltecem o fruir e o fluir, característicos de uma dinâmica pósmoderna ${ }^{1}$. Bauman prefere usar o termo modernidade líquida para caracterizar a contemporaneidade, em oposição à modernidade iniciada em torno de do século XV, definida por ele como modernidade sólida. Afora as definições de tempos caracterizados pela história em Idades, a pretensão da discussão de Bauman é mostrar que a modernidade que começa a se delinear no século XV está em agonia, desde o século XX. Com Bauman, compreendemos que estamos, depois de cinco séculos, ingressando novamente numa mudança de época. Se acompanharmos seu pensamento como balizador de nossa reflexão, estamos num tempo de superficialidades, de liquidez, em que estão presentes

* Endereço Eletrônico: prof_smaniotto@ yahoo.com.br

*** Endereço Eletrônico: ibertice@ unochapeco.edu.br os excessos e os relativismos, numa permanente e contínua tendência de desconstrução, desordem, caos e incertezas. Assim, os valores constituídos a partir da desconstrução de valores similares aos de outrora, caracterizam-se pela liquidez e volatilidade ${ }^{2}$. Os novos constructos valorativos se relativizam, configurando um estado permanente de liquidez ou perpétua conversão em líquido, por conta da sua fundamental capacidade de adaptação. Escreve Bauman, caracterizando o nosso tempo, através da metáfora do líquido:

Os fluidos se movem facilmente. Eles "fluem",
"escorrem", "esvaem-se", "respingam",
"transbordam", "vazam", "inundam",
"borrifam", "pingam"; são "filtrados",
"destilados"; diferentemente dos sólidos, não são
facilmente contidos - contornam certos
obstáculos, dissolvem outros e invadem ou
inundam seu caminho (BAUMAN, 2001, p.8,
grifos do autor).

Dizendo com outras palavras, passamos da modernidade na qual a solidez era a sua característica, para uma pós-modernidade onde a 
liquidez impõe sua acentuada marca. Por isso, passamos da "ordem" moderna para o "caos" pósmoderno (BAUMAN, 1999a), saímos da era das certezas para adentrar na incerteza.

Ancorados no pensamento de Bauman, e amparados por autores que discutem a ciência e a educação nessa mudança de época, na qual as certezas da modernidade não tendem mais a se consolidar, nem foram capazes de livrar a humanidade das suas mazelas, seguimos, com Prigogine, Morin, Kuhn, Feyerabend, Sousa Santos, rumo à discussão sobre a educação num tempo de incertezas cada vez mais perceptíveis, substituindo as verdades consolidadas pela ciência moderna.

A análise se ocupa da conjuntura da ciência e da educação, nas quais as certezas são cada dia mais frágeis e remotas. Faz-se uma retomada da questão do conhecimento, na busca de entender como ciência e educação se constituíram em campos de saber com idêntica pretensão de solidez, fundadas na perspectiva da ordem e da certeza. A seguir, faz-se breve percurso para acompanhar a trajetória da ciência e da educação, rumo a uma conjuntura contemporânea em que as ancoragens da verdade e das certezas desembocam na incerteza generalizada em que os binarismos clássicos dos tempos modernos se liquefazem, na esteira do consumismo e do mercantilismo, dos quais nem a ciência, nem a educação conseguem se desvencilhar.

\section{A construção do conhecimento: um breve excurso}

O que é conhecimento? Ou, conhecimento é
saber? $\mathrm{Na}$ antiguidade, diferentes povos desenvolveram saberes que vieram a integrar a ciência dita clássica: geometria, trigonometria, matemática, hidráulica, mecânica, lógica, astronomia... e, profusamente, conhecimentos de guerra, entre tantos outros. Como ponto de partida da reflexão sobre o conhecimento, assumamos que o que se apresenta primeiro ao homem são os diferentes fenômenos, correntemente denominados realidade, a partir dos quais foram sendo construídos saberes resultantes de demandas impostas pelos problemas da vida cotidiana. Nesse sentido, a apreensão da realidade se traduz no conhecimento ou pela sua busca -, algo que é inerente ao humano. Tomamos como exemplo a chuva. Todos nós a conhecemos, entretanto, nem todos opinamos de forma idêntica a respeito do fenômeno. Tratamos o fenômeno pelos conhecimentos do senso comum. Atribuiriam sua explicação, uns, porque estava fazendo muito calor, outros, porque o céu estava escuro, ainda outros, porque a umidade estava elevada, o vento... etc. Explicou-se o fenômeno pelo conjunto de informações de que se dispunha e que, a partir delas, construiu-se o conhecimento sobre a chuva. Apesar de ser um conhecimento primevo sobre a realidade, esse conhecimento do senso comum enseja as possibilidades de elaboração de saberes a partir, assim, de um conhecimento dito précientífico. Naturalmente, o conhecimento do senso comum baseia-se em possibilidades definidas sob critérios com baixo grau de controle, pelo que, face ao conceito de ciência moderna, é tido como conhecimento não sistematizado.

Apesar de muitos povos terem construído saberes como dispositivo para enfrentar a realidade cotidiana, os gregos, por excelência, preocuparam-se também em discutir esses saberes, ou seja impuseram-se a tarefa de produzir um metasaber, um metaconhecimento. Contrapondo-se à opinião comum, a que Platão, na era clássica da filosofia denominou dóxa (conhecimento opinativo), os gregos pré-socráticos, especialmente no séc. V a.C. estabelecem as bases daquilo que seria a ciência, denominando-a de conhecimento (que Platão denominaria epistéme), caracterizando-se como um conhecimento livre das veleidades arbitrárias. Podese dizer que a Filosofia foi a área primeira desse conhecimento mais apurado, digamos epistêmicocientífico: um metaconhecimento originário.

Como prenunciamos no parágrafo anterior, Platão, discípulo de Sócrates, é o filósofo ao qual se atribui a gênese do conhecimento científico quando opôs epistéme à dóxa. Para ele, a epistéme tem como objeto o mundo inteligível, ou seja, que dá a conhecer a essência do mundo, ou os princípios de inteligibilidade; enquanto a dóxa tem como objeto o mundo sensível, permitindo atingir apenas o ser relativo, isto é, a imagem dos princípios, a aparência (República, 479c-480a; Fedro, 247d; Teeteto, 186d, 187b). Portanto, nesse modelo de pensamento, epistéme é o conceito que originou o moderno conceito de ciência. Na sua origem, o conhecimento agrega as qualidades do que é universal, verdadeiro e bom.

Entretanto, ao amparar-nos em Hessen (1999), podemos definir o conhecimento como saberes estruturados em domínios, livres de (ou minimizadas as) contradições internas - o que não supõe divergências entre as áreas -, sendo eles: arte, religião, filosofia, e ciência. Além dos conhecimentos sistematizados, encontram-se também os conhecimentos não sistematizados do 
senso comum, que não deixam de ser conhecimento, apesar de caracterizarem-se como uma miscelânea de saberes. Diante dessa perspectiva, pode-se observar o mundo (inclusive o exemplo da origem/causa da chuva) a partir das lentes de cada um dos domínios: podem-se usar os conhecimentos não sistematizados do senso comum; ou pode-se olhar com as "lentes" da religião ou dos outros domínios, dentre eles a ciência. Se optarmos por ela, pode-se olhar o mundo a partir das suas definições e convicções sistematicamente estabelecidas ${ }^{3}$.

\section{A ciência e a educação: certezas modernas}

Cabe, neste momento, um breve bosquejo do caminho pelo qual a ciência foi se movendo desde o seu engatinhar. Se fizermos o percurso da construção da ciência veremos que a perspectiva científica surgida na Grécia Antiga tem sido dinamizada pela verdade ou pela busca dela. A natureza e a organização dos seus entes passaram a ser submetidos a leis universais, em busca da satisfação dos conceitos de beleza, justiça, bondade, unidade, verdade etc. Por conta disso, o mundo passa a se enquadrar dentro da regularidade apolínea, centrada nas exigências da emergente ciência, e a filosofia tem a tarefa de dar explicações lógico-metódicas construídas sobre argumentos sólidos e convincentes. Estabelecem-se, assim, leis que determinam como o cosmo se origina, arquitetado dentro de padrões definidos. Todavia, com Anaximandro (séc. VI a. C.) - que viveu na Grécia antes dos filósofos clássicos como Platão -, temos a natureza e seu conteúdo considerados não por um determinismo, mas, sim, com uma desordem originária (ápeiron). Heráclito, que nasceu em torno de 550 a.C., notabilizou-se pela afirmação de que ao nos banharmos duas vezes no mesmo rio, já não somos o mesmo, nem o rio é o mesmo, denotando a constituição dinâmica e em perpétua mutação da natureza, inclusive a humana. Mas vence a ordem da perspectiva científica ptolomaico-platônicoaristotélica.

Com a decadência política da Grécia, o Império Romano a aglutina como território seu, fundindo-se gradativamente as culturas grega e romana. Nesse tempo, nasce a cristandade, que com o enfraquecimento do Império Romano (séc. III), se afirma. O cristianismo ganha força (séc. IX) e passa a justificar a sua ciência, através dos seus doutores, na perspectiva ptolomaico-platônico-aristotélica, com um regramento do Universo que condissesse com ideais e movimentos "divinos". A cultura ocidental, construída amparando-se nas influências greco-romanas defendidas pela ratio cristã, conduziu esse conhecimento como sendo o detentor da verdade. Paradigmas até então tidos como imutáveis regravam as descobertas - e as "cobertas" -, centrados na fé.

Dois movimentos tiraram da rota $\mathrm{O}$ pensamento platônico-aristotélico-cristão: As reformas protestantes, que enfraqueceram a unidade do pensamento medieval, e as descobertas da astronomia, especialmente as de Copérnico. Porém, a despeito da reviravolta copernicana, a condução da ciência, na modernidade, pautou-se pelos mesmos critérios que vinham sendo conduzidos desde os gregos: a certeza. Essa postura se acentua, principalmente após o século XVII, quando pelo rigor praticado por Descartes e Newton na matematização do universo (a assim dita, em latim, mathesis universalis de Descartes, ou seja, a ciência capaz de tudo explicar, independentemente do objeto de estudo) as ciências físicas exerceram papel fundamental na condução das demais ciências que, para conquistar estatuto de ciência, tiveram que aproximar-se o quanto possível do método destas, não fazendo exceção a isto, as próprias ciências pedagógicas. Leis e princípios solidificaram-se enquadrando nos seus enunciados toda existência, mesmo imaterial. Justificada por leis, definindo toda a mecânica do universo, a ciência abarca um sentido de superioridade devido a seu método e à sua pressuposta veracidade lograda pelos seus resultados. Dessa forma, o valor veritativo dado à ciência moderna faz com que a ela seja dada uma importância maior, submetendo tudo a uma determinação legalista da ordem.

Em “O que é ciência afinal?", Alan Chalmers (1993) evoca o conceito de ciência. Afirma, numa postura de provocação de como a ciência é aceita numa concepção corriqueira. Vejamos:

Conhecimento científico é conhecimento provado. As teorias científicas são derivadas de maneira rigorosa da obtenção dos dados da experiência adquiridos por observação e experimento. A ciência é baseada no que podemos ver, ouvir, tocar etc. Opiniões ou preferências pessoais e suposições especulativas não têm lugar na ciência. A ciência é objetiva. $\mathrm{O}$ conhecimento científico é conhecimento confiável porque é conhecimento provado objetivamente (CHALMERS, 1993, p. 24).

Como vimos, corriqueiramente se utiliza o termo ciência e seus correlatos para demonstrar que 
o objeto tratado sob a ótica científica é lastreado de certeza e verdade. Cabe lembrar que, apesar de prevalecer no senso comum que a ciência tem supremacia, o conhecimento científico é um constructo humano e, portanto, passível de os humanos a utilizarem de forma benéfica, ou não. Ao cientista cabe ter a humildade de reconhecer a ciência como mutável, inclusive identificar as mazelas por ela provocadas. Há que se tomar, nesse sentido, a precaução que Gérard Fourez nos adverte:

[...] a palavra "ciência" pode por vezes "aprisionar", por exemplo, quando alguns passam a impressão de que, uma vez que se falou em cientificidade, não há nada mais a fazer senão se submeter a ela, sem dizer ou pensar mais nada a respeito. Um filósofo "crítico" ou "emancipatório" da ciência procurará, portanto, compreender como e por que as ideologias da cientificidade podem mascarar interesses de sociedade diversos (FOUREZ, 1995, p. 21).

Cria-se, na modernidade, um novo paradigma, agora pautado na racionalidade. Figuram atores reconhecidos, (entre incontáveis anônimos que a história perdeu ou fez questão de perder), Nicolau Copérnico, Kepler, Galileu, Francis Bacon, René Descartes, Newton. A partir do séc. XVII a ciência moderna centrada na razão e na empiria é tomada pela razão e ação instrumental justificada pela finalidade utilitária. É por ela que se tem como prever e modificar, é por ela que se têm os meios de agir no mundo, por ela que se concebem dispositivos para utilizar e explorar a força e os recursos materiais encontrados na natureza, controlando-a. Separaramse homem e natureza. Como forma de garantir validade à ciência, o homem se afastou da natureza, não mais fazendo parte dela. Ele a olha com um olhar de fora, e submete-a, assim, manifestando supremacia do sujeito (pesquisador) sobre o objeto (a natureza) com o pretexto de objetividade na investigação. Res cogitans (o ser humano racional) e res extensa (tudo o mais, cuja característica é a extensão), foram separados por um abismo de incomensurabilidade por René Descartes. Berticelli (2006, p. 20) afirma: "Acentuou-se de tal sorte o conceito dicotômico de sujeito e objeto, que o homem se tornou quase um desconhecido de seu próprio conhecimento". Nesse mesmo enfoque, Zygmunt Bauman, em Modernidade e ambivalência, retrata a mesma posição de Berticelli. Postula Bauman (1999a, p. 48):

A ciência moderna nasceu da esmagadora ambição de conquistar a Natureza e subordiná-la às necessidades humanas. A louvada curiosidade científica que teria levado os cientistas "aonde nenhum homem ousou ir ainda" nunca foi isenta da estimulante visão de controle e administração, de fazer as coisas melhores do que são (isto é, mais flexíveis, obedientes, desejosas de servir). Com efeito, Natureza acabou por significar algo que deve ser subordinado à vontade e razão humanas - um objeto passivo da ação com um propósito, um objeto em si mesmo desprovido de propósito e portanto à espera de absorver o propósito injetado pelos senhores humanos. O conceito de Natureza, na sua acepção moderna, opõe-se ao conceito de humanidade pelo qual foi gerado. Representa o outro da humanidade. É o nome do que não tem objetivo ou significado. Despojada de integridade e significado inerentes, a Natureza parece um objeto maleável às liberdades do homem.

Por conta dos benefícios trazidos pela ciência contemporânea, pode-se, tantas vezes, acentuar seu caráter benéfico. Mas, ao mesmo tempo que essa ciência nos proporciona benefícios individuais e coletivos, nos envolve em problemas globais ${ }^{4}$. Basta pensar nos alimentos, suplementos e medicamentos que nos trazem longevidade (para quem os pode adquirir) em contraposição aos problemas muito mais amplos como, por exemplo, as questões ambientais, os problemas políticos, culturais e sociais, enfim, problemas que geram os restos que não se encaixam nas exigências contemporâneas da aliança entre ciência e mercado. Há que se dar atenção especialmente aos resíduos humanos (humanos porque são os humanos que os produzem) de que a ciência não dá conta de reciclar, conforme nos adverte Bauman (1999b), e Ulrich Beck (2011) também, não com menores clareza e argumentos.

É com o caminho indutivo-dedutivo norteado pela disjunção, postulado a partir de uma visão determinista de natureza e de humanidade que, através da experiência objetiva, se construiu o conhecimento científico moderno. Lembramos, então, do enfrentamento de Copérnico, no século XVI, da dicotomia entre a teoria geocêntrica e a heliocêntrica e, vencendo a última, teremos a retirada da Terra do centro do universo e a colocação do Sol nesse lugar privilegiado. No século XVIII temos a dicotomia da posição lavoisieuriana da combustão do oxigênio na respiração versus a teoria do flogisto ${ }^{5}$. A teoria da evolução das espécies de Darwin (séc. XIX) opõe o evolucionismo ao criacionismo. Freud, no final do século XIX para o início do século XX nos 
retira a possibilidade de nosso autocontrole pleno: o inconsciente é o que nos governa e domina o consciente (KUHN, 1995; CHASSOT, 2011; ROSA, 2012). Dessa forma, a ciência teve, até meados do século XX, preponderante supremacia sobre os demais domínios do conhecimento, pautada no pressuposto da verdade, garantido pela construção de teorias fundadas na veracidade chancelada pela superação de outra teoria.

E a educação, como ficou nessa conjuntura? Nascidas contemporaneamente, educação e ciência modernas pautadas na certeza, uma serve-se da outra. A ciência se serve da academia para seus avanços e serve-se da educação para sua propagação. A educação se valeu das afirmações da ciência para justificar sua validade e seu intento utilitarista, sendo anunciadora da ciência com suas certezas.

\section{Século XXI: a ciência e a educação na incerteza}

Constitui-se, no alinhamento supra, um paradigma, ou seja, uma forma de ver ou interpretar o mundo que se torna dominante e passa a delinear toda atividade inerente à ciência. Thomas Kuhn (1995, p.67) define paradigma como "regras aceitas" por um grupo, ou uma comunidade de cientistas. $\mathrm{O}$ paradigma é a forma de ver e interpretar a realidade e o mundo. Dessa forma, o paradigma é o ponto nodal da construção de teorias, inclusive as educacionais. Não raras vezes, a construção de certas teorias materializa-se engessada, dificultando a aceitação de nova proposta. Na acepção de Kuhn, os paradigmas determinam a forma como é e será tratado o conhecimento científico num certo período, sendo que a mudança de paradigma ocorre quando há uma ruptura/revolução acerca das concepções de mundo, o que possibilita a emergência de um novo paradigma.

Contudo, percebe-se que a ciência e a educação modernas estão, em certo sentido, ultrapassadas. Se outrora a ciência nos apresentava leis imutáveis - sendo que muitos paradigmas ainda são válidos -, há que nos acostumarmos com uma nova postura frente aos desafios que a cada dia são postos à ciência. Feyerabend (1977, p. 71) reconhece esses limites: “[...] o conhecimento de hoje pode, amanhã, passar a ser visto como conto de fadas; essa é a via pela qual o mito mais ridículo pode vir a transformar-se na mais sólida peça da ciência".

Embora de forma discreta, o paradigma dominante, entrelaçado por certezas, está cedendo espaço a novas formas de pensar. Apesar de haver noções paradigmáticas modernas muito cristalizadas, como por exemplo, a noção mecanicista do corpo, podemos dizer que há uma mudança de paradigma? Boaventura de Sousa Santos chama a atenção de que o paradigma dominante passa por uma profunda crise por conta da revolução científica iniciada por Einstein. Tal processo é irreversível, possibilitando a emergência de um novo paradigma. Afirma ele:

[...] a identificação dos limites, das insuficiências estruturais do paradigma científico moderno é o resultado do grande avanço no conhecimento que ele propiciou. $\mathrm{O}$ aprofundamento do conhecimento permitiu ver a fragilidade dos pilares em que se funda (SANTOS, 2008, p. 41).

Boaventura de Sousa Santos (2008) caracteriza a ciência moderna como uma elaboração da razão, ao tempo em que outros conhecimentos passassem a ser refutados. A razão que Santos destaca condiz com a ordem e a estabilidade, traduzida em antinomias como sujeito/objeto, normal/anormal, civilizado/primitivo; e entre as ciências: ciências naturais/ciências humanas, ou na expressão alemã: Naturwissenschaften e Geisteswissenschaften. Trata-se de um modelo de racionalidade científica, como um modelo totalitário. Esta visão nos leva à dicotomia entre natureza e pessoa humana, e entre conhecimento científico e conhecimento do senso comum (SANTOS, 2008, p. 24). Segundo ele, a mais importante de todas as formas de conhecimento é o senso comum, já que é o conhecimento vulgar e prático com que no cotidiano orientamos nossas ações. Avalia Santos (2008, p. 88-89):

A ciência moderna construiu-se contra o senso comum que considerou superficial, ilusório e falso. A ciência pós-moderna procura reabilitar o senso comum por reconhecer nesta forma de conhecimento algumas virtualidades para enriquecer a nossa relação com o mundo ${ }^{6}$.

Nesse sentido, podemos dizer que o tempo do século XXI é um tempo diferente da modernidade, não mais das certezas mas, sim, das incertezas. Amparamo-nos em Prigogine (1996).

Zygmunt Bauman, em Modernidade $e$ ambivalência (1999a), assevera que a modernidade construiu-se sobre a ordem. Sem adentrar nas discussões da ordem na mesma dimensão do positivismo, Bauman diz que, construído por ideais divinos, o mundo simplesmente "era" e, embora irmãos gêmeos modernos, o caos foi negado e a ordem enaltecida. Embora extensa, vale precisar 
nessa citação o pensamento do eminente sociólogo, (1999a, p.14) que sentencia: "Pensamos situar-nos hoje num ponto crucial dessa aventura, no ponto de partida de uma nova racionalidade que não mais identifica ciência e certeza". E segue afirmando:

Podemos dizer que a existência é moderna na medida em que se bifurca em ordem e caos. A existência é moderna na medida em que contém a alternativa da ordem e do caos. Com efeito, ordem e caos, ponto. Se é de algum modo visada (quer dizer, na medida em que é pensada), a ordem é visada não como substituto para uma ordem alternativa. A luta pela ordem não é a luta de uma definição contra outra, de uma maneira de articular a realidade contra uma proposta concorrente. É a luta da determinação contra a ambiguidade, da precisão semântica contra a ambivalência, da transparência contra a obscuridade, da clareza contra a confusão. A ordem como conceito, como visão, como propósito, só poderia ser concebida para o discernimento da ambivalência total, do acaso do caos. A ordem está continuamente engajada na guerra pela sobrevivência. $\mathrm{O}$ outro da ordem não é uma outra ordem: sua única alternativa é o caos. $\mathrm{O}$ outro da ordem é o miasma do indeterminado e do imprevisível. O outro é a incerteza, essa fonte e arquétipo de todo medo. Os tropos do "outro da ordem" são: a indefinibilidade, a incoerência, a incongruência, a incompatibilidade, a ilogicidade, a irracionalidade, a ambiguidade, a confusão, a incapacidade de decidir, a ambivalência. O caos, "o outro da ordem", é pura negatividade. É a negação de tudo o que a ordem se empenha em ser. É contra essa negatividade que a positividade da ordem se constitui. Mas a negatividade do caos é um produto da autoconstituição da ordem, seu efeito colateral, seu resíduo e, no entanto, condição sine qua non da sua possibilidade (reflexa). Sem a negatividade do caos, não há positividade da ordem; sem o caos, não há ordem (BAUMAN, 1999a, p. 14-15).

Ao usar o termo ambivalência, Bauman está tentando discutir como foi pautada a modernidade ocidental através da dualidade entre a ordem e o caos, o bem e o mal, os amigos e os inimigos, o moral e o imoral etc., através de aspectos com a possibilidade de serem bem definidos quanto ao que é ou não é. De sorte que, desde as primeiras civilizações, a elaboração de concepções do que é bem ou mal, justo ou injusto etc., se deu pela desconstrução de antigos valores, substituídos por outros, com características bem definidas. E embora o bem e o mal trocassem de posição, essa troca era caracteristicamente definida.
Entretanto, na modernidade líquida, o que é bom passa a não ser bom, ordem cede lugar ao caos, o injusto passa a ser justo, enfim, os entes dicotômicos mudam de lugar de forma muito volátil, caracterizando uma adaptação muito relativa, muito singular, nem sempre capaz de garantir sentido à ação humana. Conviver numa conjuntura líquida é o desafio. Conviver e agir numa sociedade ambivalente é fluir na incerteza e, nessa incerteza, se circunscreve também a ação de educar.

Berticelli (2006) ampara-se em Prigogine que destaca o conceito de equilíbrio da matéria, sendo que nesse estado a matéria de nada demanda, entretanto, distante do equilíbrio, a matéria demanda interação com o ambiente. Dessa forma, Berticelli destaca situação análoga no processo de ensinoaprendizagem em tempos de falência da ordem, do equilíbrio e das certezas:

Se é possível aprender, se é possível agregar conhecimentos através do ensino, é porque há demanda para eles: há carência, necessidade e o aprendiz não está em equilíbrio, nem em relação a si, nem em relação ao meio (BERTICELLI, 2006, p.167).

A constatação supra caracteriza a educação como um processo de constante busca, quando não se está satisfeito, quando se está em situação de caos. Como se pode perceber, há uma confluência do pensamento de Berticelli com Edgar Morin. Também Morin defende a necessidade epistemológica de um paradigma que incorpore o acaso, a probabilidade e a incerteza como parâmetros necessários à compreensão da realidade a fim de superar os limites do determinismo e da simplificação. Ele nos apresenta em oposição ao paradigma clássico da simplificação, os fundamentos do novo paradigma complexo. Suas palavras:

Aprendemos, no final do século XX que, à visão do universo obediente a uma ordem impecável, é preciso substituir a visão na qual este universo é o jogo e o risco da dialógica (relação ao mesmo tempo antagônica, concorrente e complementar) entre a ordem, a desordem e a organização (MORIN, 2000, p. 83-84).

Imersos numa nova época diferente de todas até então, numa conjuntura de crises e incertezas, como pensar a educação à luz de Zygmunt Bauman? A postura de Bauman frente à educação na modernidade líquida vem no sentido de tratá-la como mais um produto a ser consumido numa cultura de ambivalências. Nessa cultura, a oferta não possibilita 
a construção de uma demanda, pois tudo o que é ofertado visa a satisfação momentânea e passageira, sendo rapidamente descartado. Postula Bauman (2008b, p.30): "Hoje, o conhecimento é uma mercadoria" e, "[...] como outras mercadorias do mercado, são produtos concebidos para serem consumido instantaneamente e de uma única vez" (p. $46)^{7}$.

Assim como o que se come ou se usa, uma vez mercantilizados, os vínculos humanos se tornaram supérfluos e a educação mercantilizada passa a ser consumida descartavelmente. Bauman (2010) nos provoca à reflexão sobre a diferença da educação na modernidade, cuja durabilidade deveria ser para a vida toda: a educação, em tempos líquidos, possui durabilidade instantânea e é consumida qual fora um fast-food. E, ironicamente, nos dá a dica de guardarmos o conhecimento no dispositivo removível, deixando o espaço do cérebro para emoções e aventuras descartáveis:

Isso é contrário a tudo que a aprendizagem e a educação representaram na maior parte de sua história. Afinal, elas foram criadas na medida de um mundo durável, que esperava permanecer assim e pretendia ser ainda mais durável do que havia sido até então. [...] Por isso, a possibilidade de armazenar todas as informações em compartimentos mantidos a uma distância segura dos cérebros [...] é uma ideia oportuna e tentadora (BAUMAN, 2010, p. 46-47).

Continua Bauman (2008b, p. 44): “A massa de conhecimento acumulado chegou a ser a epítome contemporânea da desordem e do caos". Hoje os jovens sofrem de "síndrome de impaciência" e não têm mais tempo a perder com uma educação que exige muito esforço para pouco prazer, tanto mais uma educação para a vida toda. Em tempos líquidomodernos, assim diz Bauman (2010):

A perspectiva de se ver restrito a uma única coisa a vida inteira é repulsiva e apavorante. [...] Portanto, a ideia de que a educação pode consistir em um "produto" feito para ser apropriado e conservado é desconcertante, e sem dúvida não depõe a favor da educação institucionalizada (BAUMAN, 2010, p. 41-42).

E como educação é uma mercadoria para o consumo imediato, vem ofertada em excesso. Já vem programada com a sua obsolescência e perde sua verdade rapidamente e, acima de tudo, seu poder de sedução se esvai rapidamente, pois não garante a satisfação do desejo, se é que se tenha dado condições para o desejo existir, já que uma das condições do educar é, tantas vezes, a própria interdição dele. Dessa forma, a educação pode ser avaliada na dinâmica de mercado e mensurada pela quantidade. Eis um desafio que inclui a educação na incerteza, por conta dos riscos do mercado e da não realização do desejo, que aliado à metamorfose científica, posiciona ambas - ciência e educação numa condição caótica e incerta.

\section{Considerações finais}

Tentou-se, neste estudo, demonstrar que a ciência tal como a conhecemos hoje, apesar de ser gestada na antiguidade, é uma construção humana moderna, de um período em que afirmações se tornaram leis universais com pretensão de garantir verdades inconcussas amparadas na física e na matemática. Porém, em dias atuais, o paradigma das certezas já não desfruta nem da supremacia, nem da credibilidade com as quais contou em outras eras. Está em crise, cedendo espaço a um novo paradigma: a incerteza. Dessa forma, os paradigmas da ciência já não comportam mais uma única verdade. Nesse mesmo sentido, buscou-se situar a educação nesse mesmo rumo, especialmente mercê de seu destino ao imediato "consumo" e descartabilidade.

Numa conjuntura de metamorfoses científicas, a educação pregadora das verdades prontas e acabadas não mais se sustenta. Valemo-nos da afirmação de Berticelli, que sintetiza: "Todas estas afirmações nos conduzem para muito longe das certezas, para muito longe do dogmatismo, para muito longe de sistemas estáveis, do tempo reversível mecanicista" (2006, p.149). As metanarrativas da modernidade ainda existem mas estão em crise. Há uma ruptura nas certezas sólidas do moderno, que ainda está, de certa forma, presente. O modelo moderno não dá mais conta de todos os fenômenos da contemporaneidade, mas não temos, ainda, um modelo a seguir, se é que o teremos e se é, tanto mais ainda, que o desejamos/queremos. O modelo do mercado tem sido um desses modelos utilizados para nos traçar rumos.

Coerente com discussões provocadas por Prigogine de que ciência e certeza não correm mais tão próximas; com o apoio de Kuhn, Fleck e Feyerabend que nos instigam para as mudanças de paradigmas científicos, inclusive postuladas por Santos e Edgar Morin; compactuados com a dinâmica líquido-moderna de Bauman, em que a ambivalência significa relativização, na qual estamos imersos de forma fluida e caótica; e, ainda, auxiliados 
por Berticelli, por suas concepções, asseguramos estar numa conjuntura na qual rumamos a uma educação na incerteza.

Como não é possível, neste exíguo texto, dar a sentença final, - tanto menos numa dinâmica volátil da qual todos somos partícipes, queiramos ou não -, acreditamos serem pertinente, urgentes e necessárias novas discussões sobre o assunto que já vem a meio caminho, sendo isto que ora apresentamos como apenas mais um passo nesse longo caminho de possibilidades incertas.

\section{Notas}

1 Em que pese a preferência de Bauman pelo conceito modernidade líquida, que lhe é muito peculiar, ele utiliza também a expressão pósmodernidade.

2 Poderíamos ter seguido caminho, neste estudo, na companhia de Gilles Lipovetsky que, numa série de obras desenvolve o conceito de hipermodernidade, levantando bastante exaustivamente suas características, inclusive em ética.

3 Ainda que oportuno e, de certa forma necessário, não podemos nos ater, aqui, às mais que significativas discussões ensejadas por Ludwik Fleck e Thomas Kuhn a respeito da constituição das ciências, porque isto nos levaria a ampliar sobremaneira o texto. Para esta discussão, recomendamos a leitura de Gênese $e$ desenvolvimento de um fato científico, de Ludwik Fleck e A estrutura das revoluções científicas de Thomas Kuhn. Além disto, estão disponíveis na internet inúmeros e bons artigos que discutem de forma muito competente a questão.

4 Ulrich Beck, eminente sociólogo alemão, em sua obra Sociedade de risco: rumo a uma outra modernidade. 2. ed. São Paulo: Ed. 34, 2011, faz um estudo bastante profundo em que expõe os benefícios em contraposição aos problemas que resultam da mesma fonte: o avanço tecnológicocientífico.

5 Teoria segundo a qual os metais são complexos e contêm o flogisto que, depois de perdê-lo, restam seus derivados deflogisticados. Em outras palavras, a oxidação resultante da combinação do metal com o oxigênio, numa interpretação atual. Entretanto, ao invés da oxidação, interpretava-se como se fosse uma redução. (Vide Chassot, 2011, p. 267).

6 Neste sentido, o conceito de fenômeno (fainómenon, no grego), como aquilo que se mostra, na fenomenologia inaugurada por Edmund Husserl, ganha novo status, ou seja, o conhecimento imediato, na relação sujeito-sujeito se reconhece a fonte originária do que, depois, resulta na ciência formalizada ou mediatizada. A condição para conhecer/saber o que é $\mathrm{H}_{2} \mathrm{O}$ é conhecer a água enquanto tal, enquanto fenômeno que se apresenta, que se mostra enquanto outro sujeito diferente de nós, mas que se dá a conhecer, na sua presentação originária.

7 Pequenas traduções, neste artigo, são de responsabilidade de seus autores.

\section{Referências}

BAUMAN, Zygmunt. Modernidade e ambivalência. Rio de Janeiro: Jorge Zahar, 1999a.

- Globalização e as consequências humanas. Rio de Janeiro: Jorge Zahar, 1999b.

Modernidade líquida. Rio de Janeiro: Jorge Zahar, 2001.

Zahar, 2007.

Tempos líquidos. Rio de Janeiro: Jorge

- Vida para consumo: a transformação das pessoas em mercadorias. Rio de Janeiro: Jorge Zahar, 2008a.

- Los retos de la educación en la modernidad liquida. Barcelona: Editorial Gedisa, 2008b.

Zahar, 2010.

Capitalismo parasitário. Rio de Janeiro:

BECK, Ulrich. Sociedade de risco: rumo a uma outra modernidade. 2. ed. São Paulo: Ed. 34, 2011

BERTICELLI, Ireno Antônio. Epistemologia $e$ educação: da complexidade, auto-organização e caos. Chapecó: Argos, 2006.

CHALMERS, Alan F. O que é ciência afinal? São Paulo: Brasiliense, 1993.

CHASSOT, Attico. A ciência através dos tempos. 2. ed. São Paulo: Moderna, 2011.

FEYERABEND, Paul. Contra o método. Rio de Janeiro: Livraria Francisco Alves Editora, 1977. 
FLECK, Ludwik. Gênese e desenvolvimento de um fato científico. Belo Horizonte: Fabrectum, 2010.

FOUREZ, Gérard. A construção das ciências: introdução à filosofia e à ética das ciências. São Paulo: Unesp, 1995.

HERÁCLITO de Éfeso. Fragmentos.

HESSEN, Joannes. Teoria do conhecimento. São Paulo: Martins Fontes, 1999.

KUHN, Thomas. A estrutura das revoluções científicas. 5. ed. São Paulo: Perspectiva, 1995.

MORIN, Edgar. Os sete saberes necessários à educação do futuro. 2. ed. São Paulo: Cortez; Brasília: UNESCO, 2000.
PLATÃO. A República. Trad. Maria Helena da Rocha Pereira. Lisboa, Fundação Calouste Gulbenkian, 1993.

. Diálogos. 2. ed. Trad. J. C. de Souza, J. Paleikat e J. C. Costa. São Paulo, Abril Cultural, 1979 (Coleção Os Pensadores).

PRIGOGINE, Ilya. O fim das certezas: tempo, caos e as leis da natureza. Trad. Roberto Leal Ferreira. São Paulo: UNESP, 1996.

ROSA, Carlos Augusto de Proença. Historia da ciência. 2. ed. Brasília: FUNAG, 2012. Vol. II, Tomo I.

SANTOS, Boaventura de Sousa. Um discurso sobre as ciências. 5. ed. São Paulo: Cortez, 2008.

\section{Sobre os autores}

Vanderlei Smaniotto é professor na Graduação. Graduado em Filosofia, especialista em Filosofia e Psicanálise e Mestre em Educação. Docente do Magistério Superior Substituto na Universidade Federal da Fronteira Sul (UFFS) onde ministra o Componente Curricular Filosofia da Educação. Autor do livro Século XXI: da educação das certezas à educação na incerteza. Curitiba: Editora CRV, 2017.

Ireno Antônio Berticelli é professor. Doutor em Educação pela Universidade Federal do Rio Grande do Sul (UFRGS). Docente no Programa de Pós-Graduação Stricto Sensu em Educação (Mestrado em Educação) e docente no Programa de Pós-Graduação Stricto Sensu em Ciências da Saúde (Doutorado em Ciências da Saúde) da Universidade Comunitária da Região de Chapecó (UNOCHAPECÓ). Autor de livros: A origem normativa da prática educacional na linguagem. Ijuí: Unijuí, 2004; Epistemologia e educação: da complexidade, autoorganização e caos. Chapecó: Argos, 2006; Educação em perspectivas epistêmicas pós-modernas. Chapecó: Argos, 2010.

Recebido em agosto de 2017.

Aprovado em outubro de 2017. 